\title{
DEVELOPMENT OF UHMWPE-BASED ANTIFRICTION MATERIALS
}

\author{
O. V. Gogoleva*, E. S. Petukhova \\ Institute of Oil and Gas Problems, Siberian Branch of the Russian Academy of Sciences, \\ 20 Avtodorozhnaya St., 677007, Yakutsk, Russia \\ *Corresponding author. E-mail: oli-gogoleva@yandex.ru; \\ address for correspondence: 677007, ul. Avtodorozhnaya 20, Yakutsk, Russia.
}

The paper presents research results on the development of promising polymeric composite materials based on ultrahigh-molecular polyethylene and nanostructured fillers. It is shown that the modification of UHMWPE with nanoclays halves the rate of mass wear, as well as the friction coefficient and temperature in the contact zone, increasing the strength of materials by $30 \%$ as compared to unfilled UHMWPE. Advanced polymer composites have been developed to improve the reliability, safety and efficiency of the operation of transportation and processing equipment.

Keywords: ultra-high molecular weight polyethylene, polymeric composite material, filler, supramolecular structure, friction coefficient, friction surface.

DOI: $10.17804 / 2410-9908.2017 .2 .028-033$

\section{References}

1. Okhlopkova A.A., Adrianova O.A., Popov S.N. Modifikatsiya polimerov ultradispersnymi soedineniyami [Modification of Polymers by Ultradispersed Compounds]. Yakutsk, Izd-vo SO RAN Publ., 2003, 224 p. (In Russian).

2. $\quad$ Selyutin G.E., Gavrilov Yu.Yu., Voskresenskaya E.N., Zakharov V.A., Nikitin V.E., Poluboyarov V.A. Composite materials based on ultra-high molecular weight polyethylene: properties, prospects of use. Chemistry for Sustainable Development, 2010, vol. 18, no. 3, pp. 375-388. (In Russian).

3. Okhlopkova A.A., Petrova P.N., Gogoleva O.V. Wear-resistant composite materials based on ultra-high molecular weight polyethylene meant for operation under extreme conditions. Materialovedenie, 2011, no. 9, pp. 10-13. (In Russian).

4. Andreeva I.N., Veselovskaya E.V., Nalivaiko E.I. Sverkhmolekulyarnyi polietilen vysokoy plotnosti [Ultra-High Molecular Weight Polyethylene]. L., Khimiya Publ., 1982, 80 p. (In Russian). 5. Junges Fernando, Beauvalet Mariana, Leal Bárbara C., Casagrande Adriana C. A., Mota Fábio F., Mauler Raquel S., Casagrande Jr. Osvaldo L. UHMWPE-Layered Silicate Nanocomposites by in situ Polymerization with Tris(pyrazolyl)borate Titanium/Clay Catalyst. J. Braz. Chem. Soc., 2009, vol. 20, no. 3, pp. 472-477. DOI: 10.1590/S0103-50532009000300010.

6. Brevnov P.N. Polyethylene-and montmorillonite-based nanocomposite materials: synthesis, structure, properties. Ph.D thesis, 2008. (In Russian).

7. Sleptsova S.A., Afanasieva E.S., Grigorieva V.P. Structure and tribological behavior of polytetrafluoroethylene modified with layered silicates. Journal of Friction and Wear, 2009, vol. 30, no. 6, pp. 1-7. DOI: 10.3103/S1068366609060105.

8. Myshkin N.K., Petrokovets M.I. Trenie, smazka, iznos. Fizicheskie osnovy i tekhnicheskie prilozheniya tribologii [Friction, Lubrication, Wear. Basic Physics and Engineering Applications of Tribology]. M., Fizmatlit Publ., 2007, 368 p. (In Russian).

9. Mashkov Yu.K., Ovchar Z.N., Surikov V.I., Kalistratova L.F. Kompozitsionnye materialy na osnove politetraftoretilena. Strukturnaya modifikatsiya [Polytetrafluoroethylene-Based Composite Materials. Structural Modification]. Moscow, Mashinostroenie Publ., 2005, 240 p. (In Russian). 
Подана в журнал: 02.06.2017

УДК 678.073

DOI: $10.17804 / 2410-9908.2017 .2 .028-033$

\title{
РАЗРАБОТКА АНТИФРИКЦИОННЫХ МАТЕРИАЛОВ НА ОСНОВЕ СВМПЭ
}

\author{
О. В. Гоголева*, Е. С. Петухова \\ Федеральное государственное бюджетное учреждение науки Институт проблем нефти и газа СО РАН, \\ ул. Автодорожная, 20, Якутск, Российская Федерация \\ *Ответственный автор. Электронная почта: oli-gogoleva@yandex.ru; \\ адрес для переписки: 677007, Якутск, ул. Автодорожная, 20, Российская Федерация.
}

В работе приведены результаты исследований по разработке перспективных полимерных композиционных материалов на основе сверхвысокомолекулярного полиэтилена и наноструктурированных наполнителей. Показано, что модификация СВМПЭ наноглинами приводит к понижению скорости массового изнашивания в 2 раза при снижении коэффициента трения и температуры в зоне контакта в 2 раза, при этом прочность материалов увеличивается до 30 \% по сравнению с ненаполненным СВМПЭ. Разработаны перспективные полимерные композиты для повышения надежности, безопасности и эффективности эксплуатации транспортной техники и технологического оборудования.

Ключевые слова: сверхвысокомолекулярный полиэтилен, полимерный композиционный материал, наполнитель, надмолекулярная структура, коэффициент трения, поверхность трения.

\section{1. Введение}

В последние годы на стыке различных областей науки возникли интересные направления в создании перспективных нанокомпозиционных материалов. Известно, что состав матрицы и наполнителя, их соотношение, структура и взаимная ориентация определяют требуемые сочетания эксплуатационных технологических и других специфических свойств нанокомпозитов, в которых, как правило, проявляется синергизм полезных свойств исходных компонентов неорганической и органической природы [1-4].

Прикладной интерес объясняется значительным улучшением ряда механических, теплофизических, барьерных свойств крупнотоннажных полимеров при добавлении к ним частиц наноглин, достигаемым при незначительном увеличении плотности системы благодаря низким степеням наполнения. Возможность получения наполненных полимерных материалов с повышенными модулем упругости и физико-механическими, триботехническими характеристиками делает полимер - силикатные нанокомпозиты весьма - привлекательными в производстве широкого ряда продуктов: от упаковочных материалов до конструкционных изделий $[5,6]$.

\section{2. Методики и объекты исследования}

В качестве полимерной матрицы был использован сверхвысокомолекулярный полиэтилен (СВМПЭ) марки GUR 4120 с молекулярной массой 4,7 млн. со средним размером частиц порошка - 50-150 мкм и плотностью - 936-950 кг/ $\mathrm{M}^{3}$.

Выбор СВМПЭ в качестве полимерной матрицы для наномодифицирования обусловлен тем, что он является крупнотоннажным промышленным полимером с широким спектром областей применения. С другой стороны, СВМПЭ является уникальным полимером, способным сохранять упруго-эластические свойства, сравнительно низкие и стабильные значения коэффициента трения, необходимые для обеспечения работоспособности узлов трения при 
высоких нагрузках, скоростях скольжения и в широком интервале температур. Полимерные материалы на его основе обладают высокой морозостойкостью, ударной прочностью, химической стойкостью, термической устойчивостью и износостойкостью. У подшипников из таких материалов отсутствуют явления схватывания и заедания, поэтому даже после длительного бездействия пусковой момент трения незначительно увеличивается, что важно при эксплуатации техники в условиях Севера.

Выбор слоистых силикатов вермикулита и бентонита в качестве наполнителей обусловлен их структурой, характеризуемой как природная наноструктура. Благодаря своей структуре слоистые силикаты способны эксфолиироваться в полимерной матрице на единичные слои, что приводит к формированию развитого межфазного слоя полимер/наполнитель, объем которого увеличивается при уменьшении размера частиц наполнителя [5].

Физико-механические свойства определяли на разрывной машине «Инстрон» при скорости движения подвижных захватов 50 мм/мин. Скорость массового изнашивания и коэффициент трения полимерных композитов определяли на машине трения ИИ 5018 (схема трения «диск-диск» при контактном давлении $200 \mathrm{H}$, скорости скольжения 1 м/с, контртелостальной вал из стали 45 с твёрдостью 45-50 НRC и шероховатостью $R_{\mathrm{a}}=0,06-0,07$ мкм). Скорость изнашивания оценивали по потере массы образцов в единицу времени. Момент трения фиксировали с помощью цифрового милливольтметра и рассчитывали коэффициент трения. Температуру в зоне контакта ПКМ/стальное контртело определяли термопарой, закрепленной в полимерной втулке на расстоянии 1 мм от поверхности трения.

Исследование надмолекулярной структуры разработанных материалов проводили на растровом электронном микроскопе JSM-6480LV фирмы JEOL (Япония).

\section{3. Результаты испытаний и их обсуждение}

В табл. 1 приведены результаты исследований физико-механических характеристик полимерных композиционных материалов (ПКМ) на основе СВМПЭ, содержащих наноглины, а именно - диспергированные до наноразмерного уровня бентонит и вермикулит со средним размером частиц 30-70 нм.

Таблица 1 - Физико-механические характеристики ПКМ на основе СВМПЭ и наноструктурированных наполнителей

\begin{tabular}{|l|c|c|c|c|}
\hline \multicolumn{1}{|c|}{ Состав } & $C$, мас. $\%$ & $\varepsilon, \%$ & $\delta$, МПа & $E$, МПа \\
\hline СВМПЭ & - & $340-350$ & $31-34$ & $730-740$ \\
\hline СВМПЭ + бентонит & 0,5 & $340-360$ & $40-43$ & $920-960$ \\
\hline СВМПЭ + бентонит & 1 & $330-350$ & $32-34$ & $730-740$ \\
\hline СВМПЭ + вермикулит & 0,5 & $340-360$ & $43-45$ & $930-960$ \\
\hline СВМПЭ + вермикулит & 1 & $330-340$ & $35-37$ & $750-800$ \\
\hline
\end{tabular}

Из данных табл. 1 следует, что при наномодифицировании СВМПЭ 0,5 мас. \% бентонита и вермикулита относительное удлинение при разрыве остается на уровне исходного полимера, тогда как прочность при разрыве и модуль упругости повышаются на 30-35 \%, что, вероятно, является следствием уменьшения гибкости макромолекул изза возникающих связей между частицами наполнителя и макромолекулами полимера [7]. Увеличению модуля упругости, возможно, способствуют ориентированные полимерные цепочки в слоях глины.

В табл. 2 приведены триботехнические показатели композитов, модифицированных 0,5 мас. \% вермикулита.

Установлено снижение скорости массового изнашивания до 2 раз и уменьшение коэффициента трения и температуры в зоне контакта по сравнению с ненаполненным СВМПЭ. 
Увеличение износостойкости и снижение коэффициента трения, вероятно, связано с тем, что наночастицы вермикулита способствуют увеличению адгезии пленки переноса к поверхности контртела. Это, также свидетельствует о том, что при модифицировании образуется новая структура, которая обеспечивает легкость скольжения субслоев и повышает износостойкость поверхностного слоя [8].

Таблица 2 - Триботехнические характеристики ПКМ

\begin{tabular}{|l|c|c|c|}
\hline \multicolumn{1}{|c|}{ Состав } & $I$, мг/ч & $f$ & $T,{ }^{\circ} \mathrm{C}$ \\
\hline СВМПЭ & 0,67 & 0,23 & $80-90$ \\
\hline СВМПЭ + 0,5 мас. \% + вермикулит & 0,3 & 0,17 & $65-70$ \\
\hline
\end{tabular}

Для установления влияния наполнителей на процессы структурообразования в СВМПЭ и, соответственно, на характер изменения свойств проведены структурные исследования методом электронной микроскопии.

Структурные исследования (рис. 1) показали, что морфология наполненного СВМПЭ значительно отличается от морфологии исходного полимера. Структура исходного СВМПЭ (рис. 1 a) характеризуется как ламеллярная с высокой степенью кристалличности.

Введение 0,5 мас. \% вермикулита с развитой удельной поверхностью обеспечивает существенное изменение кристаллизации, приводя к образованию различных надмолекулярных структурных элементов в СВМПЭ, имеющих четко выраженные границы (рис. 1 б).

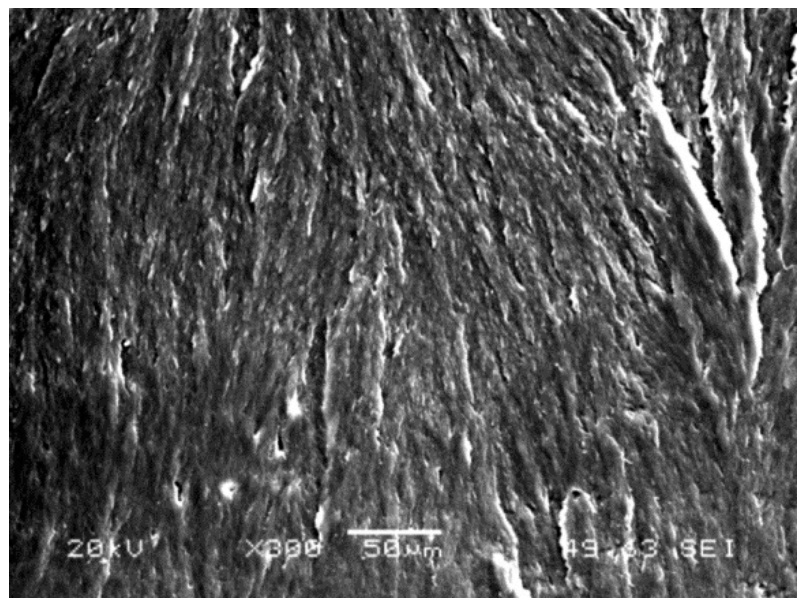

$a$

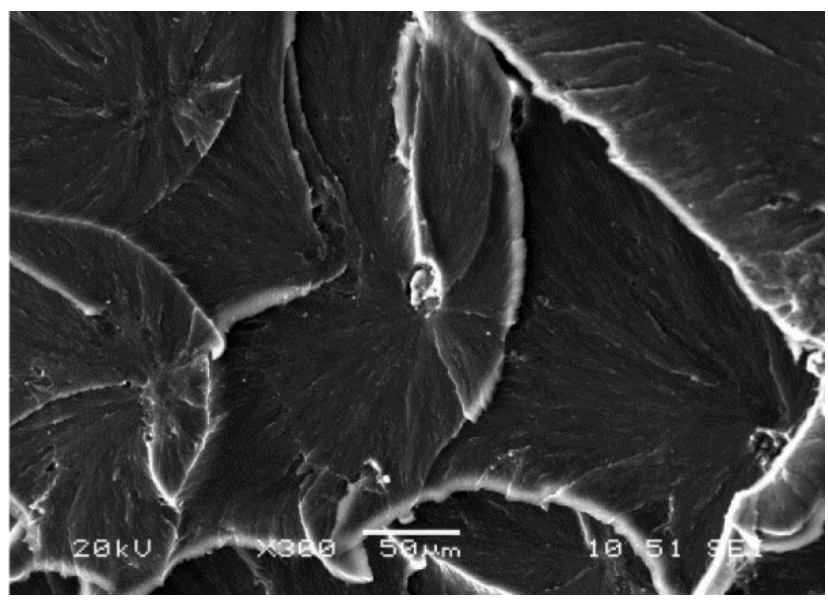

$\sigma$

Рис. 1. Надмолекулярная структура СВПМЭ:

$a$ - исходного; $\sigma$ - модифицированного 0,5 мас. \% вермикулита. Увеличение $\times 300$

Из микрофотографий следует, что частицы вермикулита являются центрами кристаллизации, от которых идет рост сферолитных образований. Образование сферолитов предпочтительнее с кинетической точки зрения, так как этот процесс требует минимальной перестройки малоподвижной структуры кристаллического полимера $[1,9]$.

Очевидно, частицы вермикулита ведут себя как искусственные зародыши структурообразования, способствуя образованию более организованной и упорядоченной надмолекулярной структуры. Именно этот композит отличается оптимальным сочетанием триботехнических и деформационно-прочностных характеристик.

Одним из факторов, определяющих механизмы трения и изнашивания полимерных систем, является структура поверхностных слоев контактирующих тел, формирующаяся в процессе эксплуатации. На рис. 2 представлены микрофотографии поверхностей трения композитов на основе СВМПЭ, модифицированных 0,5 мас. \% вермикулита. 


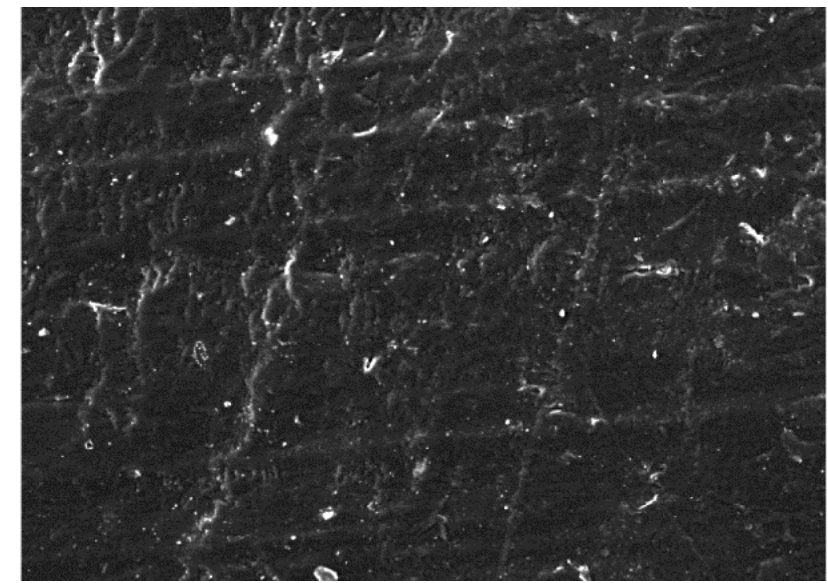

$a$

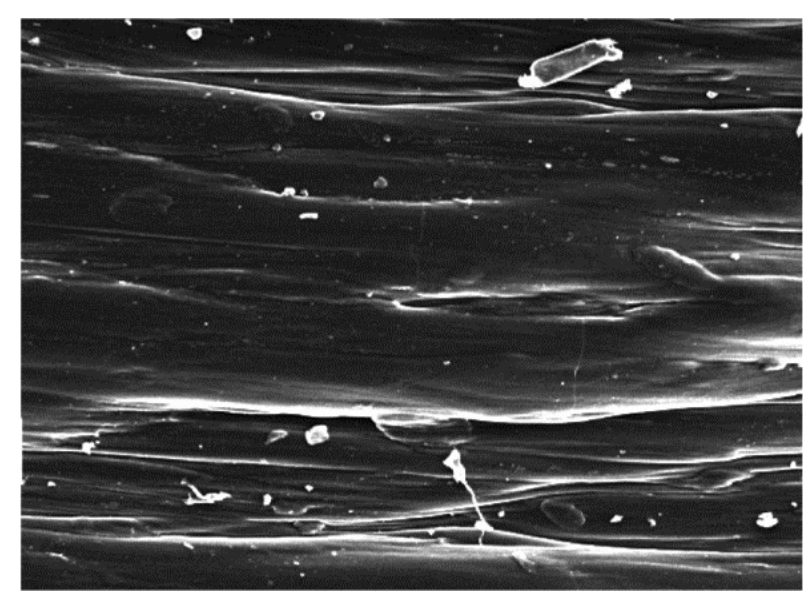

$\sigma$

Рис. 2. Микрофотографии поверхностей ПКМ: $a$ - до трения; $\sigma$ - после трения

Структуру поверхности ПКМ (рис. 2 б) после трения можно охарактеризовать как бороздчатую структуру, которая имеет вид полос различной ширины, как правило, ориентированных вдоль направления скольжения. Борозды образуются в результате пластического оттеснения материала поверхности твердыми частицами, находящимися в составе пограничного слоя.

Образование подобной структуры композита в процессе трения свидетельствует о стабильной работе трибосопряжения [8]. Износостойкость композита возросла в 2 раза, а коэффициент трения нанокомпозита уменьшился до 0,17 , что свидетельствует о пластифицирующем действии наномодификатора при трении и изнашивании композита.

\section{4. Заключение}

Результаты исследования свойств композитов на основе СВМПЭ подтверждают перспективность использования природных минералов бентонита и вермикулита в качестве модификаторов для разработки триботехнических материалов.

Показано, что модификация СВМПЭ наноструктурированным вермикулитом и бентонитом в количестве 0,5-1,0 мас. \% приводит к повышению служебных характеристик. Прочность при разрыве и модуль упругости увеличились на 30-40 \%, износостойкость повысилась в 2 раза при уменьшении коэффициента трения и температуры в зоне контакта.

Таким образом, на основании проведенных исследований разработаны новые составы композитов с высокими триботехническими характеристиками.

\section{Литература}

1. Охлопкова А. А., Адрианова О. А., Попов С. Н. Модификация полимеров ультрадисперсными соединениями. - Якутск : Изд-во СО РАН, 2003. - 224 с.

2. Композиционные материалы на основе сверхвысокомолекулярного полиэтилена: свойства, перспективы использования / Г. Е. Селютин, Ю. Ю. Гаврилов, Е. Н. Воскресенская, В. А. Захаров, В. Е. Никитин, В. А. Полубояров // Химия в интересах устойчивого развития. 2010. - T. 18, № 3. - C. 375-388.

3. Охлопкова А. А., Петрова П. Н., Гоголева О. В. Износостойкие композиционные материалы на основе сверхвысокомолекулярного полиэтилена для эксплуатации в экстремальных условиях // Материаловедение. - 2011. - № 9. - С. 10-13.

4. Андреева И. Н., Веселовская Е. В., Наливайко Е. И. и др. Сверхвысокомолекулярный полиэтилен высокой плотности. - Л. : Химия, 1982. - 80 с. 
5. UHMWPE-Layered Silicate Nanocomposites by in situ Polymerization with Tris(pyrazolyl)borate Titanium/Clay Catalyst / Fernando Junges, Mariana Beauvalet, Bárbara C. Leal, Adriana C. A. Casagrande, Fábio F. Mota, Raquel S. Mauler, Osvaldo L. Casagrande Jr. // J. Braz. Chem. Soc. - 2009. - Vol. 20, no. 3. - P. 472-477. - DOI: 10.1590/S0103-50532009000300010.

6. Бревнов П. Н. Нанокомпозиционные материалы на основе полиэтилена и монтмориллонита: синтез, структура, свойства : автореф. дис. ... канд. хим. наук : 02.00.06. - М., 2008. $24 \mathrm{c}$.

7. Sleptsova S. A., Afanas'eva E. S., Grigor'eva V. P. Structure and tribological behavior of polytetrafluoroethylene modified with layered silicates // Journal of Friction and Wear. - 2009. Vol. 30, no. 6. - P. 1-7. - DOI: 10.3103/S1068366609060105.

8. Мышкин Н. К., Петроковец М. И. Трение, смазка, износ. Физические основы и технические приложения трибологии. - М. : ФИЗМАТЛИТ, 2007. - 368 с. - ISBN 978-5-9221-0824-9

9. Композиционные материалы на основе политетрафторэтилена. Структурная модификация / Ю. К. Машков, З. Н. Овчар, В. И. Суриков, Л. Ф. Калистратова. - М. : Машиностроение, 2005. - 240 с. 